\title{
AFETIVIDADE NA SALA DE AULA: CONCEPÇÕES DE ALGUMAS DOCENTES
}

\author{
BORBA, Valdinéa Rodrigues de Souza ${ }^{1}$ \\ MACHADO, Andreza da Silva² \\ CALIMAN, Renata Aparecida ${ }^{3}$
}

\begin{abstract}
RESUMO: O presente trabalho identifica e analisa a afetividade na visão das docentes de séries iniciais. Parte do pressuposto de que a interação no meio social, os sentimentos e afetos influenciam no desenvolvimento da cognição do indivíduo. Vygotsky e Wallon, dentre outros autores, trazem importantes contribuições para fundamentar essa questão. A pesquisa foi realizada através de um questionário de sete perguntas para identificar as concepções das docentes sobre o termo afetividade. Foram entrevistadas oito docentes de séries iniciais, e, com base em suas respostas e nos referenciais teóricos, foi possível destacar a influência e relevância que o termo possui em relação à aprendizagem. Concluiu-se que esta questão é de suma importância para as docentes, e que é essencial um bom relacionamento entre educador e educando para uma aprendizagem satisfatória.
\end{abstract}

Palavras-chave: Afetividade. Emoção. Relação entre educador e educando.

\begin{abstract}
The present work identifies and analyzes the affectivity in the initial series teachers' vision. It parts from the estimated that the interaction in social way, the feelings and affections influence the development of that individuals cognition. Vygotsky and Wallon, among other authors, bring important contributions to base this question. The research was done through a questionnaire of seven questions to identify the teacher's conceptions about affectivity. Eight initial series teachers had been interviewed, and, based in their answers and the theoretical references, it was possible to detach the influence and relevance that the term has for learning. Conclusion: this question has much importance to good teacher/pupil relationship and for a good learning.
\end{abstract}

Keywords: Affectivity. Emotion. Relation between educator and educating.

\section{INTRODUÇÃO}

Este artigo apresenta um recorte da pesquisa $A$ afetividade no contexto escolar: $a$ visão de algumas docentes de séries iniciais do ensino fundamental. Traz como objetivos identificar e analisar as ações e reações das docentes diante do comportamento de seus educandos. Parte do princípio de que o ser humano, desde o seu nascimento, necessita de estar sempre ligado um ao outro. Esse fato é natural e ocorre universalmente. O ser humano constitui-se como pessoa a partir das relações que estabelece com seus pares e com o ambiente. De acordo com Vygotsky, Wallon e outros teóricos, é através das interações sociais que o sujeito desenvolve seus processos mentais superiores. Nesse sentido, as emoções vividas e a afetividade expressa nestas interações são fundamentais para desenvolvimento e aprendizagem da criança.

1 Mestre em Educação. Professora da FE/FFCL. E-mail: valdinea@feituverava.com.br

2 Graduanda - Normal Superior

3 Graduanda - Normal Superior 
Nas séries iniciais, esta questão é fundamental, pois, nesse período, o educando vive em constante relação com o docente, querendo expressar seus desejos, emoções; fazendo questionamentos e procurando aprender através das informações e conhecimentos mediados pelo docente. $\mathrm{O}$ vínculo afetivo que se estabelece entre educador e educando pode se tornar um facilitador nos processos de ensino e aprendizagem.

De certa forma, essa ligação está relacionada a sentimentos como amor, ódio, alegria, saudade, segurança, confiança, enfim, sentimentos esses que todas as pessoas experimentam e que estão ligados à afetividade.

$\mathrm{Na}$ vida escolar, percebe-se que o docente astuto, mesmo dominando bem o conteúdo a ser ministrado, não consegue, muitas vezes, fazer com que os educandos aprendam. No entanto, quando os docentes deixam os alunos à vontade para expressarem seus sentimentos, alegrias, angústias, interesses, descobertas e medos, os mesmos sentem-se mais à vontade com o professor, e isso parece ser um fator facilitador da aprendizagem.

No processo ensino-aprendizagem, essa relação afetiva é tão importante quanto necessária, pois o educando criança se espelha no docente, copiando suas atitudes e princípios.

Verifica-se que a afetividade tem uma concepção ampla, englobando sentimentos (origem psicológica) e emoções (origem biológica). Segundo Wallon (1978), ela tem um papel fundamental no decorrer de todo o desenvolvimento do indivíduo. Nos primeiros meses de vida, tem a função de comunicação através dos impulsos emocionais. Para o autor, é na relação com o outro, na sua interação social que a criança interage com o meio em que vive e passa a ter conhecimento de mundo.

Assim, a relação docente - educando não é algo mecânico, mas, sim, troca de conhecimentos e experiências. Desta forma, é salutar que exista entre educador e educando um vínculo afetivo positivo, capaz de tornar suas aulas prazerosas, significativas e reflexivas, o que aumentará, nos educandos, gradativamente, a motivação para aprender.

\section{AFETIVIDADE E A RELAÇÃO EDUCADOR - EDUCANDO NA FORMAÇÃO DE PROCESSOS MENTAIS SUPERIORES}

A Lei de Diretrizes e Bases da Educação Nacional (LDBEN), a Lei 9.394/96, oferecenos os dois mais importantes princípios de afetividade e amor no âmbito escolar, o respeito à liberdade e o apreço à tolerância e nos ideais de solidariedade humana. Ambos têm, por fim último, o pleno desenvolvimento do educando, seu preparo para o exercício da cidadania ativa e sua qualificação para as novas ocupações no mundo do trabalho.

Wallon, pesquisador francês com formação em Medicina e Filosofia, que dedicou grande parte de seus estudos à afetividade e as emoções, defende que as emoções são de extrema importância para o ser humano. O ser humano, em toda sua vida, interage, convive em um meio, uma sociedade, relacionando-se com outras pessoas, e seu processo de desenvolvimento dá-se a partir dessa interação. Ressalta que todas as pessoas precisam da comunicação com o 
outro, sendo que a emoção, para o bebê, pode significar um caminho de sobrevivência. Por isso, desde seu nascimento, o homem precisa de relacionar-se com outros seres humanos e objetos.

[...] O outro age visando a atender às necessidades do recém-nascido, mas também simplesmente para comunicar-se com ele: o adulto sorri, conversa com o bebê, canta para ele. Desenvolve-se, entre o bebê e o adulto que lhe cuida, uma intensa comunicação afetiva, um diálogo baseado em componentes corporais e expressivos. (GALVÃO, 1995, p.60-61).

Sem afeto não há motivação, interesse, perguntas e, conseqüentemente, não haveria inteligência. A afetividade está ligada à inteligência, é necessária na formação de pessoas seguras, éticas, críticas, felizes e capazes de conviver em uma sociedade diversificada.

Certamente, a criança se espelha nos adultos e se deixa levar pela atração que o outro exerce sobre si. Então, ela copia, imita as atitudes, ações e reações do outro com os quais interage em seu meio social. Na escola, onde se trabalha muito com a inteligência e com as interações sociais, isso não é diferente.

Wallon apud Almeida (1999, p.51) destaca: "a afetividade e a inteligência constituem um par inseparável na evolução psíquica, pois ambas têm funções bem definidas, e, quando integradas, permitem à criança atingir níveis de evolução cada vez mais elevados".

Vygotsky (1994) destaca a importância do outro não só no processo de construção do conhecimento, mas também de constituição do próprio sujeito e de suas formas de agir.

Segundo o autor, o processo de internalização envolve o social e o individual. Afirma que "todas as funções no desenvolvimento da criança aparecem duas vezes: primeiro, entre pessoas (interpsicológica), e, depois, no interior da criança (intrapsicológica)" (ibidem, p.75).

Tanto Vygotsky quanto Wallon afirmam que não se pode separar afetividade de cognição. Para Wallon (1971), ambas não se mantêm como junções exteriores uma à outra, [...] "estão envolvidas em um processo de integração e diferenciação". (GALVÃO, 1999, p.45).

Para Wallon (1978), a afetividade, além de ser uma das dimensões da pessoa, é uma das fases mais antigas do desenvolvimento, pois o homem, logo que deixou de ser puramente orgânico, passou a ser afetivo e, da afetividade, lentamente, passou para a vida racional. Nesse sentido, afetividade e inteligência se misturam, havendo o predomínio da primeira e, mesmo havendo uma diferenciação entre as duas, haverá uma permanente reciprocidade entre elas. [...] "a afetividade depende, para evoluir, de conquistas realizadas no plano da inteligência, e viceversa". (DANTAS, 1992, p.90).

Wallon (1979, p. 207-8) destaca a importância da escola para o educando desde a mais tenra idade:

A escola maternal parece ser perfeitamente adequada para preparar a emancipação da criança, que vive ainda encaixada na sua vida familiar onde sabe distinguir mal a sua personalidade do lugar que ai ocupa e onde a representação que se faz de si mesma tem algo de global, de confuso e de exclusivo. [...] encontra-se com outras da mesma idade, e entre as quais não existe a distinção da mais velha e da mais nova. [...] 


\section{A COLETA DOS DADOS}

Após extenso trabalho de pesquisa bibliográfica, as pesquisadoras saíram a campo, com a intenção de levantar e coletar dados. Marconi (1990) entende pesquisa de campo como:

[...] aquela utilizada com o objetivo de conseguir informações e/ou conhecimentos acerca de um problema, para o qual se procura uma resposta, ou de uma hipótese, que se queira comprovar ou, ainda descobrir novos fenômenos ou as relações entre elas. (p.95)

Para tanto, utilizou-se, como instrumento, um questionário semi-estruturado, elaborado com o objetivo de investigar as concepções e reflexões das docentes sobre afetividade.

Esta pesquisa iniciou-se, buscando compreender como as docentes vêem a questão da afetividade na relação docente-educando, pois o docente é o elemento chave no processo educativo. Segundo Cervo; Bervian (1983, p.50) “A pesquisa é uma atividade voltada para a solução de problemas, através do emprego de processos científicos”. Para Gil (1987, p.136), a pesquisa é um "procedimento racional e sistemático que tem como objetivo proporcionar respostas aos problemas que são propostos".

Foi aplicado o questionário em oito docentes das séries iniciais, ou seja, de primeira a quarta série que atuam em escolas públicas e particulares das cidades de Ituverava e Aramina, cidades situadas no interior do estado de São Paulo.

Com a finalidade de destacar suas opiniões sobre afetividade, cada docente respondeu sete questões sobre o assunto, sendo que as respostas foram pessoais, de acordo com seus conhecimentos prévios e respondidas individualmente.

As perguntas feitas às docentes foram as seguintes:

1) $\mathrm{O}$ que você entende por afetividade?

2) Que importância você atribui à afetividade?

3) Para você, qual a relação entre afetividade e desenvolvimento?

4) Em sua opinião, em qual faixa-etária a afetividade é mais importante?

5) Você acredita que a afetividade é importante na relação educador - educando?

6) Como você gostaria que seus educandos se comportassem?

7) Quais atitudes ou comportamentos de seus educandos mais a afetam?

Através do material coletado no decorrer da pesquisa, foi possível relacionar reflexões de diversos autores e as concepções sobre afetividade deflagradas nas respostas das docentes.

\section{ANALISANDO OS DADOS COLETADOS}

Todas as docentes pesquisadas tentaram expressar suas opiniões, pois cada qual respondeu segundo seu ponto de vista, e embasaram suas respostas em suas próprias experiências de vida (senso comum), e algumas buscaram fundamentos teóricos. 
Em certas respostas, percebe-se que algumas educadoras não conseguiram se expressar muito bem, pois, nem sempre, responderam ao que foi perguntado. Outras se preocuparam em dar respostas científicas, ou seja, embasadas em pressupostos teóricos.

Vale ressaltar que, em relação à primeira questão, sete educadoras relacionam afetividade com amizade, carinho, respeito, amor, dedicação, ou seja, relacionam afetividade, emoções e sentimentos, assim como os autores pesquisados que também, afirmam que a relação positiva do educador com o educando é importante para se alcançar a aprendizagem do mesmo.

As pesquisadoras concordam com as educadoras, quando estas afirmam que a afetividade é importante em todas as faixas etárias, pois é inerente ao ser humano a vontade de receber afeto, atenção, carinho, na relação com o outro.

Wallon (1971-1978) também ressalta que a afetividade é ainda mais importante quanto menor a idade do sujeito que está em período de formação da personalidade. Essa premissa nos leva a crer que, nas séries iniciais, foco de pesquisa deste trabalho, a afetividade é extremamente importante, pois os afetos, sejam eles positivos ou negativos, irão ajudar a construir, a formar a personalidade de cada indivíduo de forma muito particular e intensa.

Uma reflexão extremamente relevante sobre as implicações da teoria de Wallon para a educação, especificamente sobre o papel do educador, nos é apresentada por Almeida (2000, p.86).

Wallon, psicólogo e educador, legou-nos muitas outras lições. A nós professores duas
são particularmente importantes. Somos pessoas completas: com afeto, cognição, e
movimento, e nos relacionamos com um aluno, também pessoa completa, integral,
com afeto, cognição e movimento. Somos componentes privilegiados do meio de
nosso aluno.

Ressalta-se que, teoricamente, todas as docentes pesquisadas, compreendem o que é afetividade e qual sua importância no processo de aprendizagem, pois suas respostas se encontram em acordo com as idéias dos autores estudados.

Pode-se destacar que 95\% das educadoras relacionam a afetividade como sendo um sentimento de importância para o desenvolvimento do indivíduo.

Percebe-se que o que mais afeta as educadoras é a falta de interesse de seus alunos, e que $90 \%$ das docentes colocam o educando como responsável pelo próprio desinteresse em sala de aula. Esse dado leva a crer que as mesmas, talvez, mesmo inconscientemente, estejam tentando isentar-se de quaisquer responsabilidades pelo fracasso de seus educandos. Isso parece ser um grave equívoco, que somente irá prejudicá-los no processo ensino e aprendizagem, pois se entende que o desinteresse dos educandos pela aula também é culpa do educador.

Refletindo sobre este problema, Basso (1996) afirma que é muito importante que educando e educador estejam ligados afetivamente, pois, assim, o primeiro será mais compromissado em aprender.

Concebe-se que o educador é o principal mediador nas interações escolares. Portanto, cabe a ele conhecer melhor as características, as potencialidades, as dificuldades, os interesses 
e aspirações de sua clientela, para, desta forma, planejar suas aulas, escolher estratégias e materiais adequados à realização dos objetivos por ele propostos, bem como, motivar seus educandos de forma que ambos, educando e educador, sintam-se realizados e bem-sucedidos. Assim, o sucesso do educador depende do sucesso de seus educandos.

\section{CONCLUSÃO}

Entende-se que as questões abarcadas nesta pesquisa são fundamentais para a construção de uma Educação de qualidade, tanto nas escolas públicas quanto particulares. Isso porque não existe aprendizagem sem a construção de conhecimentos. Não existe construção de conhecimentos sem a ação dos sujeitos, sem o comprometimento de todos os envolvidos neste processo. Não existe comprometimento em relações vazias de afeto, sem motivação, sem o estabelecimento de vínculos afetivos. Sem vínculos afetivos, sem sentimentos, as interações sociais e escolares tornam-se frias, distantes e 'coisificadas', e estas relações distantes podem prejudicar a aprendizagem dos educandos.

Entende-se que a diferença está nas atitudes dos docentes. Quando o docente dá oportunidade para o educando exprimir suas expectativas, tirar suas dúvidas, opinar, demonstrar seus sentimentos, enfim, quando ele vê o educando como um ser integral, que pensa, age e, também, sente suas aulas tornam-se mais atraentes, interessantes e produtivas.

Sem dúvida, docentes mais afetivos permanecerão nas lembranças de seus educandos para sempre, ficarão presentes nos corações e mentes daqueles que um dia estudaram com eles, pois, em suas aulas, primavam por um relacionamento mais humano, afetivo e alegre. Com certeza, eles sabiam ouvir seus educandos, analisar os fatos e, posteriormente, ajudálos, provocando-lhes reflexões, aconselhando-os e promovendo-lhes novas e significativas aprendizagens. Seus conselhos os acompanharão até a vida adulta, pois, com sensibilidade, respeito e sabedoria souberam mostrar o certo e o errado, promoveram a construção de novos conhecimentos e estabeleceram, com os seus educandos, limites e regras.

Portanto, cabe a todos os educadores que atuam nas séries inicias do ensino fundamental, repensar seu papel e suas atitudes em relação a seus educandos. É imperativo que o educador se conscientize de que ele é primordial no processo de construção de conhecimentos de seus educandos, bem como na própria constituição destes como pessoas. Ele é o elemento chave que conduzirá os educandos ao sucesso ou ao fracasso, dependendo da forma como desenvolve o seu trabalho!

\section{REFERÊNCIAS}

ALMEIDA, A.R.S. A emoção na sala de aula. Campinas: Papirus, 1999.

ALMEIDA, L.R. de. Wallon e a educação. In: HENRI Wallon: psicologia e educação. São Paulo: Loyola, 2000. 
BARDIN, L. Análise de conteúdo. Lisboa/Portugal: Edições 70, 1977.

BASSO, I.B; BARGNARA, I.T.R. O desinteresse escolar: um estudo das implicações pedagógicas no processo de aprendizagem. Caderno Pedagógico, p.11-12/151-163, 1996.

BORBA, V.R. de S. A afetividade no discurso das professoras de Educação Infantil. Ribeirão Preto: 2005. Dissertação (Mestrado). Centro Universitário Moura Lacerda.

CERVO, A.L.; BERVIAN, P.A. Metodologia cientifica. 3.ed. São Paulo: McGraw-Hill do Brasil, 1983.

DANTAS, H. A afetividade e a construção do sujeito na psicogenética de Wallon. In: TAILLE, Y. de; OLIVEIRA, M.K.; DANTAS, H. Piaget, Vygotsky, Wallon: teorias psicogenéticas em discussão. São Paulo: Summus, 1992.

FREIRE, P. Pedagogia da autonomia: saberes necessários à prática educativa. São Paulo: Paz e Terra, 1996.

GALVÃO, I. Henri Wallon: uma concepção dialética do desenvolvimento infantil. Petrópolis: Vozes, 1995.

LEONTIEV, A.N. O desenvolvimento do psiquismo. Lisboa: Livros Horizonte, 1978.

LURIA, A.R. A construção da mente. São Paulo: Ícone, 1992.

MARCONI, M. A.; LAKATOS, E. M. Técnicas de pesquisa. 2.ed. São Paulo: Atlas, 1990.

OLIVEIRA, M.K. de. Vygotsky: aprendizado e desenvolvimento - um processo sóciohistórico. São Paulo: Scipione, 1993.

REGO, T.C. Vygotsky: uma perspectiva histórico-cultural da educação. 14.ed. Petrópolis: Vozes, 1995.

VYGOTSKY, L.S. A formação social da mente. São Paulo: Martins Fontes, 1984.

A construção do pensamento e da linguagem. São Paulo: Martins Fontes, 2000.

WALLON, H. As origens do caráter na criança. São Paulo: Difusão Européia, 1971.

. A evolução psicológica da criança. Lisboa/Portugal: Edições 70, 1978.

. Do acto ao pensamento: ensaio de psicologia comparada. Lisboa: Moraes, 1979. 
